Acta Horticulturae et Regiotecturae 1

Nitra, Slovaca Universitas Agriculturae Nitriae, 2020, pp. 40-43

\title{
THE EFFECT OF THE STORAGE ON THE CONTENT OF THE MALVIDIN-3-GLUCOSIDE IN RED WINE
}

\author{
Ivo SOURAL ${ }^{1 *}$, Petr ŠNURKOVIČ ${ }^{1}$, Eva TOMÁNKOVÁ ${ }^{1}$, Astrid FORNECK ${ }^{2}$ \\ ${ }^{1}$ Mendel University in Brno, Czech Republic \\ ${ }^{2}$ University of Natural Resources and Life Sciences, Austria
}

\begin{abstract}
Anthocyanins are plant dyes responsible for the colour of red wine. Of these, malvidin-3-glucoside is the most significant member and its content was monitored in wines that were first left to age in oak barrels for 12 months, subsequently bottled and sealed with plastic/cork stoppers. The malvidin-3-glucoside content was also studied in the same wines that were bottled right away without aging in barrels. Analyses were conducted within the time spans of 3 to 30 months. The highest malvidin-3-glucoside concentrations were found in month 3 of the aging process, and they significantly decreased in month 6 and month 15 of storing. Between month 15 and month 30 of storing, the content of malvidin-3-glucoside basically remained unchanged. The results of the measurements show that to preserve higher malvidin-3-glucoside levels for longer periods of time, it is better to store wine in barrels rather than in bottles and when a bottle is used instead of a barrel, a plastic stopper is better than a cork stopper.
\end{abstract}

Keywords: wine, malvidin-3-glucoside, storage, barrel aging, plastic/cork stopper

Anthocyanins and derivatives thereof are essential pigments responsible for the colouring of red wine (He et al., 2012). Anthocyanins are dyes of a plant origin that accumulate in the hypodermal cell layer of the skin of berries of the Vitis genus as they ripen. Rather high anthocyanin levels in grapes correlate with a quantity of sugars (Soural et al., 2015). The dyes are released from the skins of grapes during the process of vinification. Structurally, anthocyanins are heteroglycosides that consist of the sugar component and aglycone (anthocyanidin). Anthocyanins are rather unstable and are subject to a degradation process, which is influenced by a number of factors such as temperature, light, level of oxygen etc. (Mezey et al., 2016). Monomeric anthocyanins, with their colour being pH-dependent (Tománková et al. 2016), are responsible for the colour of young red wines, and they become highly unstable when their concentrations rapidly fall and they become involved in the production of much more stable oligomeric and polymeric structures as red wines age (Fulcrand et al., 2006). These new colourful compounds are entirely responsible for the colouring of rather old red wines; they have also become less sensitive to changed $\mathrm{pH}$ and more resistant to discolouring by sulphur dioxide by that time (Somers, 1971). Malvidin-3-glucoside is the substance most frequently occurring in young red wines; malvidin is found as a monoglucoside and is present already in blue grapes (Čopíková et al., 2005). Balík, Kumšta and Rop (2013) even report that out of more than 20 types of anthocyanins, malvidin-3-glucoside constitutes over $60 \%$ of all anthocyanins in Blaufränkisch as well as other grape varieties.

\section{Material and method}

\section{Wine}

Two wines (Blaufränkisch \& Cuvee from the wine region Moravia, GPS of vineyard: $48^{\circ} 51^{\prime} 54.0^{\prime \prime} \mathrm{N}, 16^{\circ} 53^{\prime} 24.0^{\prime \prime} \mathrm{E}$ ) aged in oak barrels, 50 litres of each, for 12 months, subsequently were decanted using 0.7 I bottles; plastic $(\mathrm{P})$ and cork $(\mathrm{C})$ stoppers were used, each having a length of $45 \mathrm{~mm}$ and a diameter of $25 \mathrm{~mm}$. In parallel, the same wines were bottled straight away without being retained in barrels, using again cork (C) or plastic $(\mathrm{P})$ stoppers.

The wines were stored in a wine cellar in the municipality Velké Bílovice in the Czech Republic in the dark and at a temperature of $12^{\circ} \mathrm{C}$ and analysed for the level of malvidin3-glucoside (MvGl), in the course of 3 to 30 months. On a day before taking the measurements, the wines were placed in a refrigerator at $5{ }^{\circ} \mathrm{C}$. The analysis was carried out in month $3,6,15,21$ and 30 of aging on Faculty of Horticulture in Lednice (Mendel University in Brno, Czech Republic).

\section{Solid phase extraction (SPE)}

Before applying a sample of wine, SPE columns ( $6 \mathrm{ml} .500 \mathrm{mg}^{-1}$ of polystyrene-divinylbenzene) were flushed with $6 \mathrm{ml}$ of acidified methanol $(0.01 \% \mathrm{HCl}$ in vol. \% in pure methanol at HPLC grade $>99.9 \%$ ) and, subsequently, with acidified water (again, $0.01 \% \mathrm{HCl}$ in vol. \%). The sample was diluted to $1: 1$ with acidified water when $6 \mathrm{ml}$ was applied to the SPE column (any non-polar MvGl was absorbed). Then there was an action of washing using $6 \mathrm{ml}$ of acidified water

Contact address: Ivo Soural, Mendel University in Brno, Faculty of Horticulture, Department of Post-Harvest Technology of Horticultural Products, Valtická 337, Lednice 69144, Czech Republic, e-mail: ivo.soural@mendelu.cz 
to remove the polar substances. The elution of MvGl was made using $6 \mathrm{ml}$ of acidified methanol.

\section{Concentrating the samples}

The eluent was made more concentrated by evaporation of the solvent (by increasing the temperature to $+35^{\circ} \mathrm{C}$ under inert atmosphere using a flow of gaseous nitrogen). The resulting dry matter was subsequently dissolved with $1 \mathrm{ml}$ of the mobile phase A (see the Liquid chromatography chapter) and filtered using a nylon syringe filter, pore size of $0.22 \mu \mathrm{m}$ (Membrane Solution); the solution was diluted, as necessary, with the mobile phase $A$ for measuring liquid chromatography (LC).

\section{Liquid chromatography}

Malvidin-3-glucoside was analysed using LC (Thermo Electron, Finnigan ChromQuest) on a column Synergy (Phenomenex, Torrance, CA, USA) with parameters: $5 \mu \mathrm{m}$, $250 \mathrm{~mm} \times 4.6 \mathrm{~mm}$, the temperature of $35^{\circ} \mathrm{C}$, the flow rate of $0.5 \mathrm{ml} \cdot \mathrm{min}^{-1}$. The mobile phase A was $5 \%$ acetonitrile $+5 \%$ formic acid (in vol. \%) in water; the mobile phase B was $55 \%$ acetonitrile $+5 \%$ formic acid (in vol. $\%$ ) in water. The gradient was increased from $6 \%$ mobile phase $B$ to $20 \%$ of B during 20 min; from $20 \%$ of B to $40 \%$ of B during $15 \mathrm{~min}$; from $40 \%$ of $B$ to $60 \%$ of $B$ during $5 \mathrm{~min}$; from $60 \%$ of B to $90 \%$ of B during 5 . The injection volume was $5 \mu \mathrm{l}$. Diode array detector (Thermo Electron, Finnigan UV6000LP) with the detection of wavelengths at 210, 280 and $520 \mathrm{~nm}$ was used for analyzing. Wavelength $520 \mathrm{~nm}$ was used for the quantitative evaluation. For the calibration, the analytical standard malvidin-3-glucoside (from PhytoLab at HPLC grade $\geq 95.0 \%$ ) was used (retention time 26.8 min.).

\section{Results and discussion}

As the wine aged, malvidin-3-glucoside (MvGl) levels were on the decrease. The highest values were recorded in month 3 of aging; during the subsequent months $(6,15,24$ and 30), lower values were recorded each time. The decline in MvGl was rendered by power or exponential characteristics (Fig. 1, Fig. 2a and details in Fig. 2b) rather than by the linear one (for example, the regression coefficient seen for the MvGl level in Blaufränkish wines stored in bottles with plastic stoppers was $R=0.9243$ for the power characteristic, $R=0.8340$ for the exponential characteristic, and only $R=0.7970$ for the linear characteristic). A rapid decrease in monomeric anthocyanins was observed by Zafrilla et al. (2003) as well.

For Cuvee, the average MvGl levels in month 3 of storing were around $35 \mathrm{mg.l}^{-1}$ (34.3 for cork; 38.0 for plastic and 36.3 for barrels); in month 6 , they were around $16 \mathrm{mg}^{.} \mathrm{l}^{-1}$ for wines stored in bottles (15.8 $\mathrm{mg.l}^{-1}$ under cork stoppers and 16.0 mg..$^{-1}$ under plastic stoppers), while in barrels, the content was significantly higher ( $26.8 \mathrm{mg}^{-1} \mathrm{l}^{-1}$, which is approximately $2 / 3$ higher than in bottles; see Fig. 1). A similar situation occurred in the subsequent months when in month 15, 24 and 30 the Cuvee's MvGl concentrations were around $3 \mathrm{mg.l}^{-1}$ when stored in bottles with cork/plastic stoppers; however, after 12 months of aging in barrels and subsequent bottling (using cork/plastic stoppers), Cuvee had the MvGl concentration of around $6 \mathrm{mg}^{-1} \mathrm{l}^{-1}$, i.e., roughly twice as much (Fig. 1).

Similar trends in the course of the MvGl concentration were found in Blaufränkisch (Fig. 2a). However, in month 3 of storing, there was approximately $70 \mathrm{mg}^{-l^{-1}}$ of $\mathrm{MvGl}$ in the barrel, while in bottles (both types of stoppers), there was only around $50 \mathrm{mg.l}^{-1}$ (48.9 for cork; 55.6 for plastic), which means that generally, the level in barrels was 35\% higher than in bottles (45\% under cork stoppers, about $28 \%$ under plastic stoppers). Within month 6, the difference was as much as nearly $40 \%$, while in barrels there was $28.0 \mathrm{mg}^{-1}$ of MvGl and in bottles (both types of stoppers) there was an average of $20.2 \mathrm{mg.l}^{-1}$, when, again, in wines under plastic stoppers there was a little higher concentration. The MvGl concentration in month 15 was in fact identical for all types of storage; it was around $3 \mathrm{mg} . \mathrm{l}^{-1}$. In the subsequent months of storage, significantly higher levels were measured in the samples with 12 months of aging in barrels than in those stored only in bottles during the storage period. For the wine that aged in barrels for 12 months and was stored under cork and plastic stoppers for another period of 12 months, the MvGl levels were 12.8 and $11.4 \mathrm{mg}^{-1}{ }^{-1}$, respectively, while the wine stored under stoppers for 24 months contained only $4.6 \mathrm{mg}^{\mathrm{I}^{-1}}$ (cork) and $3.0 \mathrm{mg}^{-\mathrm{l}^{-1}}$ (plastic). This hence, practically, constituted 4-fold differences in terms of the MvGl content. Within month 30 of storing, this ratio even increased to about an 8-fold difference between the wine stored only in bottles and the one aging in barrels for 12 months and stored in bottles for another period of 18 months.

For nine out of ten cases of Cuvee, it was characteristic that they reached lower values when stored only in bottles than when they were left aging in barrels for 12 months. The same applied to Blaufränkisch as nine out of ten cases were

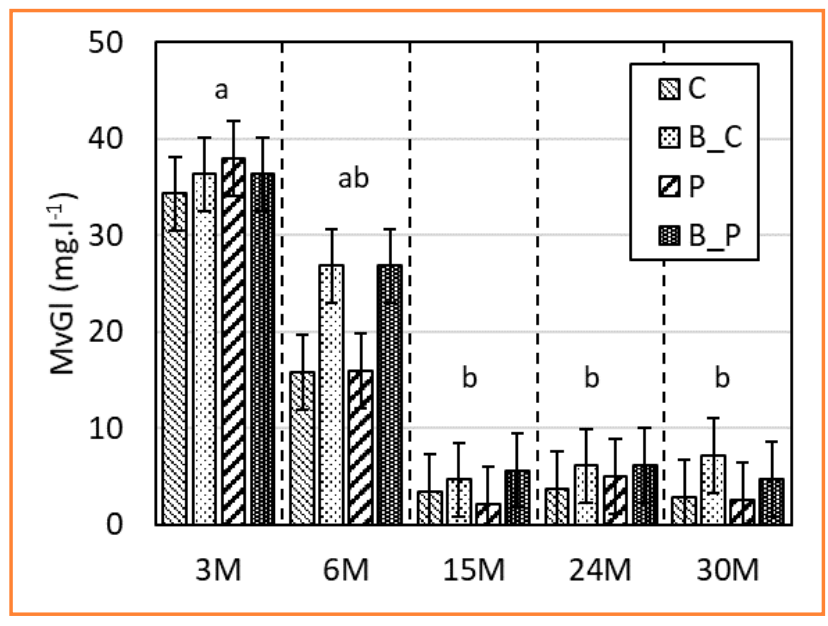

Figure 1 Distribution of malvidin-3-glucoside (MvGl) in Cuvee wine stored in bottles with cork (C) or plastic $(P)$ stoppers during the aging period of 30 months (30M means 30 months) and the one stored in oak barrels (B) for the initial 12 months and, subsequently, in bottles with cork/plastic (C/P) stoppers; different letters $(a, b)$ in the time of storage indicate a significant difference in contents of MvGl by Tukey test $(P=0.05)$; for each variant, there were 3 or 4 repetitions made 


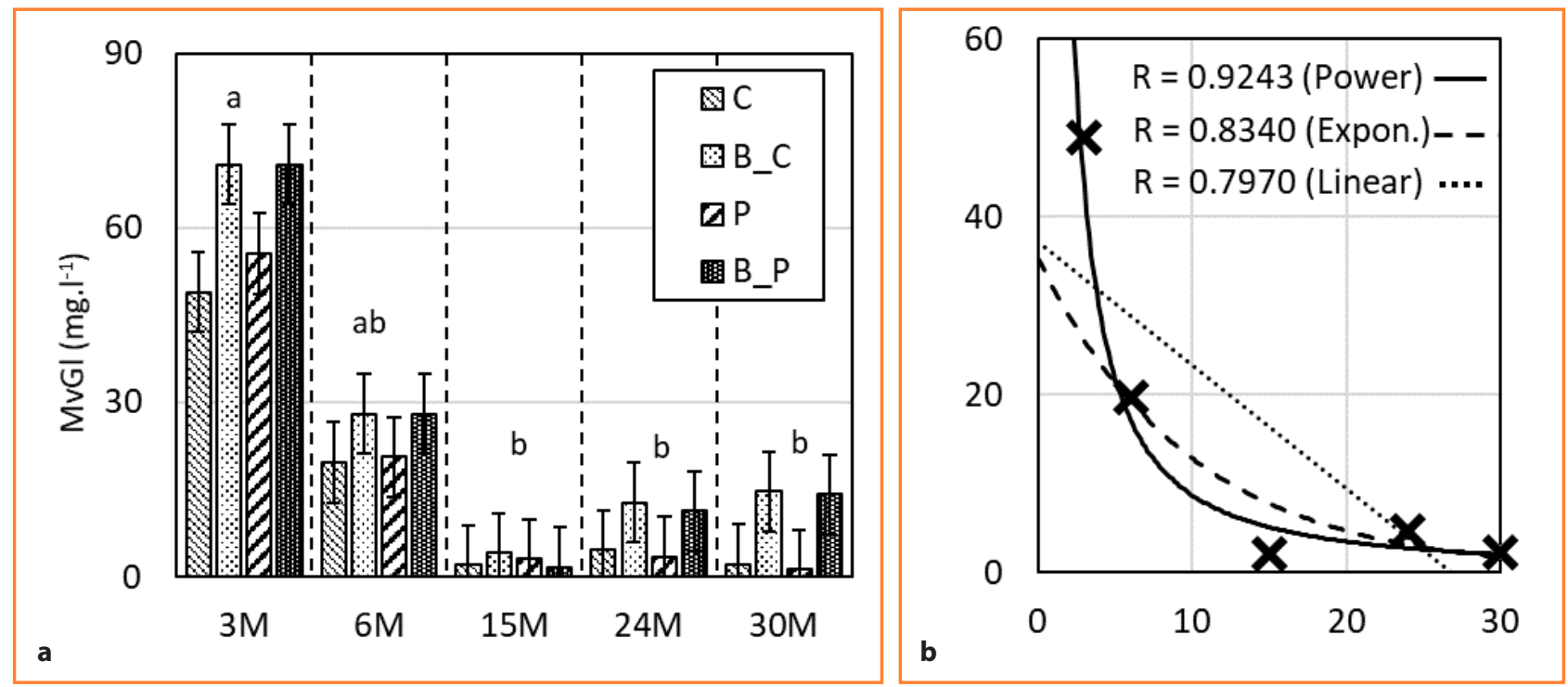

Figure 2 a - Distribution of malvidin-3-glucoside (MvGl) in Blaufränkisch wine stored in bottles with cork (C) or plastic (P) stoppers during the aging period of 30 months (30M means 30 months) and the one stored in oak barrels (B) for the initial 12 months and, subsequently, in bottles with cork/plastic (C/P) stoppers; different letters $(a, b)$ in the time of storage indicate a significant difference in contents of MvGl by Tukey test $(P=0.05)$; for each variant, there were 3 or 4 repetitions made

b - In detail, (P) with 3 test curves to decrease MvGl, regression coefficients $(R)$ were obtained by the dependence of level of MvGl on time of aging

found to have higher MvGl levels when wine was left aging in barrels.

In both Cuvee and Blaufränkisch stored under plastic stoppers, in six out of ten cases, the MvGl levels were higher than in those, found in wines under cork stoppers. In the case of Cuvee aging in barrels for 12 months, two out of three cases were observed to have higher MvGl levels compared with Cuvee wine stored under plastic stoppers, whereas the opposite was true for Blaufränkisch when three out of three cases were found to have lower MvGl levels when stored under plastic stoppers compared with those using cork; the differences, however, were significantly below $2.5 \mathrm{mg} . \mathrm{l}^{-1}$.

Zafrilla et al. (2003) monitored MvGl levels in wine for the Monastrell variety stored in glass bottles in the dark when the concentration was $49.9 \mathrm{mg}^{-1}{ }^{-1}$ for the conventional wine and $75.9 \mathrm{mg}^{-1} \mathrm{l}^{-1}$ for the ecological wine in month 3. The levels became reduced when they reached $39.2 \mathrm{mg}^{\mathrm{I}^{-1}}$ (a 21\% decrease) and $47.1 \mathrm{mg.l}^{-1}$ (a 38\% decrease) in month 6. As a part of our measurements made between month 3 and 6 of storing, the reduction of $26 \%$ was recorded in Cuvee when stored in barrels (i.e., in the dark); for storing in bottles, however, a decrease of more than $50 \%$ was recorded for the same wine stored in bottles. Concerning Blaufränkisch wine, the reduction ranged from $59 \%$ to $63 \%$ for all of the storing options. The declines between month 3 and 6 of storing are therefore in tens of $\%$.

The reduction of all anthocyanins (i.e., not only that of $\mathrm{MvGl}$ ) during the storage was measured previously by Mazza et al. (1999) when the total quantity of anthocyanins expressed as MvGl declined by $25 \%$ (from $469 \mathrm{mg}^{-1}$ to $352 \mathrm{mg.l}^{-1}$ ) after 2 months for Cabernet Franc, by 22\% (from $455 \mathrm{mg}^{-\mathrm{I}^{-1}}$ to $355 \mathrm{mg.l}^{\mathrm{I}^{-1}}$ ) after 6 months for Merlot, and by 25\% (from $219 \mathrm{mg.l}^{-1}$ to $166 \mathrm{mg.l}^{-1}$ ) after 5 months for Pinot Noir.
A similar percentual decline (by 20\%) was recorded by Gómez-Plaza et al. (2002) when they determined, for the Monastrell variety stored in bottles, the malvidin level to be

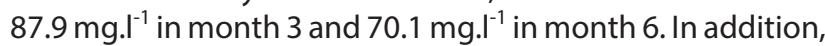
they measured the content of $41.1 \mathrm{mg} . \mathrm{l}^{-1}$ even in month 12 . However, this was a decrease of 53\% compared with month 3. For the samples measured by us in month 15 , the declines ranged between $84 \%$ and $95 \%$ for Cuvee and between $94 \%$ and $98 \%$ for Blaufränkisch. During one-year period of the storage, the declines are already several tens of percent.

\section{Conclusion}

The present study compared four methods of a wine-storing: in bottles with plastic (P) or cork (C) stoppers, aging in oak barrels for initial 12 months and subsequent bottling using stoppers of plastic (B_P) or cork (B_C), and the effect of these on the malvidin-3-glucoside (MvGl) content. The effect was studied during the storage period from 3 to 30 months in the case of the Blaufränkisch and Cuvee varieties. The decline of $\mathrm{MvGl}$, concerning time, was rendered by the power $(R=0.9243)$ or exponential $(R=0.8340)$ characteristics rather than by the linear one $(R=0.7970)$ as shown by the values for Blaufränkish $(P)$. This shows a rapid decline in $\mathrm{MvGl}$ in the early days of the storage when after month 15 , the MvGl quantities practically remained unchanged. In 18 out of 20 cases, the MvGl levels were higher in wines stored in barrels for the initial 12 months compared with those stored in bottles. For wines aging in bottles only, the MvGl levels were higher in six out of ten cases when wines were stored under plastic stoppers compared with those stored under cork stoppers. Between month 3 and month 6 of storing, the reduction of $26 \%$ was recorded for Cuvee stored in barrels; in the case of storing the same variety in bottles, however, even more than $50 \%$ reduction was observed. For Blaufränkisch, 
the reduction ranged between $59 \%$ and $63 \%$ for all storing options. The declines measured between month 3 and month 6 therefore reached tens of percent. When stored in one-year period, instances of the MvGl level reduction were extremely significant; for example, they ranged, from month 3 to month 15, between $84 \%$ and $95 \%$ and between $94 \%$ and $98 \%$ for Cuvee and Blaufränkisch, respectively. Hence, the results of the measurements show that to preserve the higher levels of MvGl for a longer period, it is better to store wine in barrels than in bottles and when one does use bottles instead of barrels, plastic stoppers are better for use than cork stoppers.

\section{Acknowledgements}

This work was supported by the project CZ.02.1.01/0.0/0.0/1 6_017/0002334. Research Infrastructure for Young Scientists is co-financed from Operational Programme Research, Development and Education.

\section{References}

BALÍK, J. - KUMŠTA, M. - ROP, O. 2013. Comparison of anthocyanins present in grapes of Vitis vinifera $L$. varieties and interspecific hybrids grown in the Czech Republic. In Chemical Papers, vol. 67, 2013, no. 10, pp. 1285-1292.

ČOPÍKOVÁ, J. - UHER, M. - LAPČÍK, O. - MORAVCOVÁ, J. - DRAŠAR, P. 2005. Přírodní barevné látky. In Chemické listy, vol. 99, 2005, pp. 802-816.

GÓMEZ-PLAZA, E. - GIL-MUÑOZ, R. - LÓPEZ-ROCA, J. M. MARTÍNEZ-CUTILLAS, A. - FERNÁNDEZ-FERNÁNDEZ, J. I. 2002. Maintenance of Colour Composition of a Red Wine During Storage. Influence of Prefermentative Practices, Maceration Time and Storage. In Lebensmittel-Wissenschaft \& Technologie, vol. 35, 2002, pp. $46-53$.
FULCRAND, H. - DUENAS, M. - SALAS, E. - CHEYNIER, V. 2006. Phenolic reactions during winemaking and aging. In American Journal of enology and viticulture, vol. 57, 2006, no. 3, pp. 289-297. HE, F. - LIANQ, N. N. - MU, L. - PAN, Q. H. - WANG, J. - REEVES, M. J. - DUAN, C. Q. 2012. Anthocyanins and their variation in red wines. II. Anthocyanin derived pigments and their color evolution. In Molecules, vol. 17, 2012, no. 2, pp. 483-519.

MAZZA, G. - FUKUMOTO, L. - DELAQUIS, P. - GIRARD, B. - EWERT, B. 1999. Anthocyanins, Phenolics, and Color of Cabernet Franc, Merlot, and Pinot Noir Wines from British Columbia. In Journal of Agricultural and Food Chemistry, vol. 47, 1999, pp. 4009-4017.

MEZEY, J. - CZAKO, P. - MEZEYOVÁ, I. - BAJČAN, D. - KOBOLKA, R. 2016. Changes of Selected Antioxidant Parameters of Red Wines during Maturation. In Czech Journal of Food Science, vol. 34, 2016, no. 4, pp. 356-361.

SOMERS, T.C. 1971. The polymeric nature of wine pigments. In Phytochemistry, vol. 10, 1971, pp. 2175-2186.

SOURAL, I. - BALÍK, J. - WENDELIN, S. - EDER, R. 2015. Analyses of Compounds in Skins, Pulps and Whole Berries of Thirty-Three Austrian Table Grape Cultivars. In Acta Horticulturae, vol. 1079, 2015, pp. 527-534.

TOMÁNKOVÁ, E. - BALÍK, J. - SOURAL, I. - BEDNÁŘ, P. PAPOUŠKOVÁ, B. 2016. Colour and antioxidant properties of malvidin-3-glucoside and Vitisin A. In Acta Alimentaria, vol. 45, 2016, no. 1, pp. 85-92.

ZAFRILLA, P. - MORILLAS, J. - MULERO, J. - CAYUELA, J. M. MARTÍNEZ-CACHÁ, A. - PARDO, F. - LÓPEZ NICOLÁS, J. M. 2003. Changes during Storage in Conventional and Ecological Wine: Phenolic Content and Antioxidant Activity. In Journal of Agricultural and Food Chemistry, vol. 51, 2003, no. 16, pp. 4694-4700. 